\title{
Teoria histórico-cultural e intervenções pedagógicas: possibilidades e realizações do bom ensino
}

Historical-cultural theory and pedagogical interventions: possibilities and achievements of good teaching

\author{
Marta Chaves* \\ Universidade Estadual de Maringá \\ Silvana Calvo Tuleski** \\ Universidade Estadual de Maringá
}

Elieuza Aparecida de Lima***

Universidade Estadual Paulista Júlio de Mesquita Filho

Cyntia Graziella G. Simões Girotto****

Universidade Estadual Paulista Júlio de Mesquita Filho

Resumo Este texto tem por objetivo refletir e socializar práticas educativas e experiências de formação em serviço realizadas em municípios dos estados do Paraná e São Paulo, como desdobramento de pesquisas, projetos e cursos de extensão. A presente elaboração contempla estudos sobre a organização do ensino, e pauta-se na Teoria HistóricoCultural, que ampara as intervenções pedagógicas para a Educação Infantil e o Ensino Fundamental. A Teoria Histórico-Cultural é apresentada como referencial teórico para uma proposta de atuar em uma perspectiva de humanização e emancipação. Assim, para que os procedimentos didáticos sejam ricos de significado, a comunicação, a afetividade e a escolha de recursos e procedimentos devem figurar como características essenciais no processo de ensino.

PALAVRAS-CHAVE: Teoria Histórico-Cultural, Intervenções pedagógicas, Educação infantil e Ensino Fundamental.

Abstract This text has the objective of reflecting and socializing the educational practices and experiences of formation in service carried out in cities of the states of Paraná and São Paulo, as deployment of researches, projects and extension courses. The present elaboration contemplates studies on the organization of teaching and it is guided according to the Historical-Cultural Theory, which sustains the pedagogical interventions to Children Education and Basic Education. The Historical-Cultural Theory is presented as a theoretical reference for a purpose of acting in a humanization and emancipation perspective. Therefore, so that the didactic procedures be rich in meaning, the communication, the affection and the choice of the resources and procedures must act as essential characteristics in the teaching process.

KEYWORDS: Historical-cultural theory, Pedagogical interventions, Children's education, Primary schooling. 
Este texto tem por objetivo refletir e socializar práticas educativas e experiências de formação em serviço, realizadas em municípios dos estados do Paraná ${ }^{1} \mathrm{e}$ São Paulo ${ }^{2}$, como desdobramento de pesquisas, projetos e cursos de extensão realizados pelas autoras e colegas de militância na Educação Infantil. Nessas realizações efetivadas, temos organizado, tanto para a Educação Infantil, quanto para os primeiros do Ensino Fundamental, propostas de práticas educativas que, embora de forma incipiente e modesta, envolvem grande esforço de coordenadores pedagógicos e educadores que pautam suas intervenções junto às crianças nas elaborações da Teoria Histórico-Cultural, referencial teórico e metodológico para organizar o trabalho pedagógico.

Apresentamos, aqui, uma breve referência aos estudos bibliográficos e intervenções pedagógicas desenvolvidos desde o ano de 2002, no Estado do Paraná e, desde 2001, no Estado de São Paulo. Destacamos algumas realizações, contemplando expoentes das artes plásticas visuais e da Literatura Infantil, por oferecerem possibilidades de procedimentos e recursos didáticos fundamentais para a realização de práticas educativas, por meio das quais educadores e crianças podem ter acesso às riquezas humanas elaboradas em diferentes períodos históricos.

As experiências de estudo e formação realizadas defendem que as unidades educativas podem se apresentar como espaços de educação por excelência. O que equivale a afirmar que, nessa perspectiva a rotina, ou seja, a organização do tempo e do espaço, só se justifica se for plena de práticas educativas que impulsionem a aprendizagem e o desenvolvimento, o que pressupõe que o brincar e o aprender devem figurar como os objetivos principais das intervenções pedagógicas (GIROTTO; SOUZA, 2010; CHAVES, 2008; 2011a; LIMA; VALIENGO, 2011).

Consideramos que, se, nas salas e espaços ocupados por crianças, apresentarmos com intencionalidade os mais variados recursos com diversificadas cores, formas, letras, números e brinquedos - possíveis de serem identificados em telas, músicas, poesias e histórias -, isto pode constituir-se em referência e modelo para uma infância que, nesta sociedade capitalista, tem conhecido tão somente a miséria. Rotineiramente, testemunhamos crianças e adultos que não alcançam condições mínimas de dignidade, forma bruta que se manifesta, em muitos casos, nas condições de estudo e trabalho de professores em unidades escolares de todo o território brasileiro; condição que os impede de efetuar práticas pedagógicas mais consequentes em favor de uma educação para a autonomia e a valorização das potencialidades humanas.

Em oposição a esse contexto e apoiados nos escritos da Teoria HistóricoCultural, retomamos continuamente a tese central de que as ações pedagógicas devem projetar a criança para além daquilo que ela já sabe, conforme enuncia Vigotskii (1988), para quem o bom ensino é aquele que vai adiante do desenvolvimento, fazendo-o avançar. Essa projeção da criança exige estudos e práticas pedagógicas focadas na formação e no aperfeiçoamento de funções psíquicas superiores - as qualidades especificamente humanas, formadas e apropriadas no conjunto das relações e atividades vivenciadas por cada pessoa. Dentre elas, citamos as formas voluntárias de atenção, memória, percepção; o raciocínio lógico-matemático; a imaginação; o domínio da conduta.

Com o objetivo de fazer avançar o desenvolvimento dessas funções, nas crianças, as práticas pedagógicas, nas unidades escolares, organizam-se e dirigem-se 
intencionalmente para mobilizar o uso e o exercício de formas cada vez mais sofisticadas de memória, atenção, percepção, pensamento, emoções e linguagem, dentre outras (VYGOTSKI, 1995). Para isso, os educadores enriquecem e diversificam as propostas educativas, intencionando envolver as crianças, dentre outras práticas sociais, nas de leitura e contação de histórias, brincadeira de papéis sociais ou de faz-de-conta, rodas de conversas, apreciação de produções artísticas com telas, músicas e poesias, como já salientamos. Sobre essa questão, comungamos com Leontiev (1978) e Vygotski (1995): o processo de formação de funções psíquicas superiores acontece mediante condições propícias de vida, atividade e educação, que requerem solidez de princípios, objetivos e escolhas metodológicas.

Neste sentido, a Psicologia Histórico-Cultural ou Teoria Histórico-Cultural apresenta-se como referencial teórico para uma proposta de atuar em uma perspectiva de humanização e emancipação. Assim, para que os procedimentos didáticos sejam ricos de significado, a comunicação, a afetividade e a escolha de recursos e procedimentos devem constar como características essenciais no processo de ensino. Nesse propósito de educação, recorremos aos ensinamentos de Blagonadezhina (1969), quando propala que os sentimentos estéticos se desenvolvem mais quando se apresentam escritos para as crianças, com desenhos de qualidade, e, quando a criança ouve e é ensinada a apreciar a boa música.

A partir dessa premissa, as práticas educativas devem priorizar a musicalização, procedimentos didáticos com telas, o ensinar a encantar-se por personagens de histórias, pelo ritmo e movimento das poesias e canções. Consideramos que, com estratégias e recursos adequados, seja possível levar as crianças a estágios cada vez mais avançados de aprendizagem e desenvolvimento, como propõem os escritos do referencial teórico referido. Desse modo, apresentar em detalhes as telas de Portinari, brincar e dançar com as letras de Vinícius e Toquinho, contextualizar o autor, ilustrador e obra nos momentos de leitura e contação de histórias e atividades literárias decorrentes, permitir a constituição de autoria do leitor durante os processos de leitura com a retextualização configuram-se intervenções pedagógicas que apresentam às crianças e educadores as máximas elaborações humanas. O valor estético, a beleza e o rigor dos traçados e da escrita, por sua condição de encantar, constituem, como assinalam Smirnov, Leontiev, Rubinshtein e Tieplov (1969), reais condições para que as produções humanas sejam herdadas por todos.

\section{Teoria histórico-cultural: contribuições para a realização do bom ensino}

Um dos desafios apresentados aos educadores, neste início de século XXI, é a reavaliação das práticas educativas efetuadas nas unidades escolares. Quando tratamos da formação dos educadores, a preocupação com a capacitação em serviço é potencializada. Nesse âmbito, uma proposta de educação que discuta as potencialidades das crianças e a necessidade da intencionalidade educativa em favor da emancipação implica, necessariamente, discutir a potencialidade dos professores, muitas vezes negada, nos cursos de formação ou em sua própria atuação profissional. Isso posto, um dos elementos centrais para a elaboração deste texto foi a organização de propostas de capacitação em exercício em municípios dos estados do Paraná e São Paulo. A prioridade, nestas ocasiões, centrou-se no planejamento de estudos, cujos desdobramentos se materializariam em intervenções e recursos didáticos. 
Assim, escolher as músicas, poesias e histórias que devam fazer parte da organização permanente dos trabalhos das escolas de Educação Infantil requer, antes da organização do trabalho pedagógico propriamente dito, estudos e decisões coletivas. Isto favorecerá a compreensão de que, em todo tempo, e, em todos os espaços, as unidades educativas devem estar repletas de coloridos e sons, em oposição às dezenas de instituições nas quais os brinquedos e outros recursos não são disponibilizados às crianças, a não ser em dias e horários em que estas são "autorizadas" a brincar.

Igual situação se repete com livros fora do alcance das crianças. Somandose a isto, a organização do espaço que enfatiza a preparação da criança para os anos seguintes de escola, o que marca uma concepção de criança e educação que, como afirmam Mello e Faria (2005), prioriza a antecipação da escolarização, e, com isto, se minimizam o tempo e o espaço das brincadeiras e aprendizagens coletivas.

Nesse processo de formação em serviço, a partir de questões como a organização do espaço e do tempo, buscamos valorizar estudos e intervenções educativas afetas às artes e à Literatura Infantil, temáticas centrais e responsáveis por agregar o máximo de procedimentos com, e para, as crianças. Isso equivale a postular que os autores da Teoria Histórico-Cultural (VYGOTSKI, 2007; SMIRNOV, LEONTIEV, RUBINSTEIN e TIEPLOV, 1969; MUKHINA, 1996) são essenciais para respaldar uma prática educativa em que se favoreça o entusiasmo e a educação artística, como leciona Vigostsky no conjunto de sua obra.

Como afirmamos anteriormente, o trabalho realizado junto aos educadores procura eleger músicas, histórias e poesias como essenciais para a organização do trabalho pedagógico. Seu objetivo é priorizar os estudos oriundos da Teoria Histórico-Cultural na proposta de formação em serviço, em cursos e outras vivências de formação, como por exemplo: reuniões pedagógicas, por compreendermos que as práticas educativas - como o trabalho com Literatura Infantil - favorecem a realização de intervenções pedagógicas relativas as diferentes linguagens, e, portanto, são capazes de favorecer o desenvolvimento linguístico e intelectual das crianças. Com isso, os projetos desenvolvidos nos municípios citados privilegiaram estudos e elaboração de recursos didáticos afetos à Literatura Infantil.

Em relação à promoção de situações de lúdicas, de leitura e de contação de histórias significativas às jovens gerações e seus educadores, temos empreendido esforços coletivos para a composição de trabalhos pedagógicos potencial e intencionalmente dirigidos para as mediações necessárias entre a criança e a cultura em sua plenitude e riqueza. Para essa composição, como já apontamos, (re)organizamos ou estruturamos princípios e objetivos orientadores das nossas escolhas didático-metodológicas, especialmente a organização dos espaços, dentre esses lugares para as crianças brincarem, lerem, se relacionarem com adultos e outras crianças; espaços voltados para as possibilidades de apropriação e objetivação cultural.

Nos momentos de decisões e estudos coletivos com professores de municípios do interior paulista e paranaense, vislumbramos espaços como as brinquedotecas. Compreendemos, por meio das assertivas de Mukhina (1996), que a brincadeira é uma atividade vital, nos primeiros anos de vida, mobilizadora do uso de capacidades mentais cruciais para o desenvolvimento da personalidade e da inteligência das crianças. Com essa tese como guia das nossas opções didáticas, planejamos e organizamos 
espaços, tempos e situações no dia-a-dia escolar, na educação infantil ou nos anos iniciais do Ensino Fundamental, com a pretensão de envolver completa e inteiramente as crianças. Constituímos, com objetos da cultura - araras de roupas e fantasias; mesas para as pinturas, colagens, recortes; cestos e estantes com brinquedos industrializados e com materiais reciclados; livros nos cantos que contam tanto da literatura, da música e da poesia; produções de artistas plásticos visuais; texturas, formas e cores em objetos e papéis - espaços para brincar, para acessibilidade aos brinquedos e para a atuação de crianças brincantes, como defende Vigotsky (2007); espaços que reclamam a intencionalidade dos adultos e a atividade e composição criadora das crianças, pois tal como Luria (1994b, p. 46) afirma:

são instilados estes métodos e formas de conduta na criança, em primeiro lugar, devido às demandas feitas pelo ambiente a ela; estas demandas e condições são precisamente os fatores que ou podem estancar ou podem estimular o desenvolvimento dela. Exigindo-se da criança que trabalhe formas novas de adaptação, podem-se criar súbitas transformações em seu desenvolvimento. Assim, obtemos "formações indubitavelmente culturais" que fazem um papel mais importante na evolução da criança.

Tendo compreendido a necessidade de se organizar o trabalho nessa perspectiva, é importante definir o ponto de partida dos encaminhamentos a serem efetivados. Professores e equipe pedagógica elaboram planos de trabalhos educativos, processo nos quais a organização de coletâneas com telas, músicas, poesias e arquivos de textos informativos configura-se como um procedimento que servirá de apoio para as crianças realizarem atividades com biografias de expressões da arte e da literatura.

Destacamos, aqui, um trabalho especial que se faz com a biografia dos compositores, pintores e escritores. Conhecer e estudar a vida dessas expressões é essencial antes de planejar e elaborar procedimentos didáticos com e para as crianças, negandose, então, a conduta mais comum, com base apenas em informações fragmentadas de autores e algumas poucas obras, de imediatamente planejar ou repetir os procedimentos propostos às crianças.

É comum observar "atividades" que, em geral, desencantam as crianças, como as velhas cópias mimeografadas, ou agora - com os ditos "avanços tecnológicos" - fotocopiadas, muitas das quais são reproduções de materiais apostilados sem nenhuma participação das crianças, sem que elas tenham conhecido todo o processo de elaboração (muitas vezes estes também ausentes para os próprios professores), restando-lhes, tão somente, a realização das tarefas, as quais são executadas sem sentido e significado.

Nesse processo, as ações tidas como rotineiras - recortar, colar, pintar, desenhar - que, na maioria das vezes, se configuram como execução de tarefas áridas e exaustivas para as crianças, podem ser de fato atividades significativas e favorecedoras da aprendizagem e do aprimoramento intelectual de quem aprende e de quem ensina. Essas condições propícias de aprendizagens se dão pela atitude e lugar ativos assumidos pelas crianças que, de fato, colam, brincam, recortam, modelam, pintam e também pelos educadores que, conscientes de sua atuação intelectual e mediadora, podem cultivar práticas pedagógicas voltadas para as atividades infantis significativas. 
É necessário que os educadores estejam movidos pela perspectiva que se aprende a recortar, recortando; a desenhar, desenhando, e, em lugar de "facilitar" para a criança práticas sociais essenciais a seu desenvolvimento cultural, pois, não ocasionalmente, é comum os adultos recortarem, colarem e desenharem pelas crianças. Reafirmamos que os ensinamentos de Leontiev (1988) e Vygotski (1995), expoentes da Teoria Histórico-Cultural, nos encaminham para procedimentos metodológicos baseados no princípio da atividade de cada pessoa (adulto e criança) como elemento potencializador de aprendizagens capazes de elevar os níveis de humanização ao longo da vida.

Consideramos, tal como Vygotsky e Luria (1994), que a criança resolve uma tarefa prática com a ajuda não somente dos olhos e mãos, mas também da fala, e é justamente tal unidade, nascida da conjugação da percepção, fala e ação, que a conduz às formas especificamente humanas de comportamento. Quando compreendemos que são esses estímulos auxiliares (no caso aqui a fala) que levam a cabo a função específica de organizar o comportamento, servindo como meio de autoinfluência, de autoexcitação, produzindo uma forma nova e superior de atividade na criança. Quando, ainda temos claro que a formação dessa unidade humana complexa de fala e operações práticas é produto de um processo profundamente arraigado de desenvolvimento no qual a história individual é unida de perto à história social. Dessas três proposições, evidenciamos a importância do educador não fazer as atividades pela criança, mas demonstrar a ela como fazer, dirigindo seu comportamento pelas instruções verbais que regulam os modos sociais de uso dos instrumentos escolares (caderno, lápis, régua, tesoura, cola, etc.), o que, de acordo com Vygotsky e Luria (1994), faz com que a situação como um todo adquira para o infante um significado social, em que as pessoas agem da mesma maneira que fazem os objetos.

Outro ponto importante reside no fato de que o objetivo posto pelo educador para a atividade pedagógica, externalizado para a criança, juntamente com suas orientações e instruções de como, por que e para que fazer, permite a geração de um campo psicológico absolutamente novo para a ação infantil, propiciando o aparecimento da função de formação de intenção e planejamento prévio da ação propositada. Primeiro, a intenção e o planejamento são postos pelo outro, mas isto cria condições para que a criança internalize tais modos de conduta e vá adquirindo a capacidade de planejar.

Para esses autores, o comportamento do ser humano é produto do desenvolvimento de um sistema maior de ligações sociais e relações consideradas formas coletivas de comportamento e co-operação social, e, por isso, o desenvolvimento das funções psicológicas superiores deve ser visto como parte da formação social da criança, "como a história da transformação de meios de comportamento social em meios de organização psicológica individual” (VYGOTSKY; LURIA, 1994, p.138).

Assim, na avaliação e apresentação de uma proposta de trabalho às crianças, pode ser decisivo conhecer e ensinar os encantos das poesias de Mario Quintana, encantar-se com os traçados firmes de Portinari, envolver-se com as curiosas estratégias de personagens de Tatiana Belinky. Para esse fim, voltamo-nos com especial atenção para a organização e elaboração de diversos recursos didático-pedagógicos, fundamentados na premissa de que todos os envolvidos na Educação Infantil e no Ensino Fundamental devem ter lugar ativo nas realizações pedagógicas. Imbuídos dessa in- 
tenção, organizamos as denominadas Caixas que Contam Histórias (LIMA; VALIENGO, 2011), As oficinas de leitura (GIROTTO; SOUZA, 2010) e a proposição do Ler, contar e encantar crianças na Biblioteca Escolar (GIROTO; SOUZA, 2009), Caixas de Encantos e Vida ${ }^{3}$ por exemplo. Como temos defendido, neste texto, nossa perspectiva é conhecer novas possibilidades didáticas para novas projeções e elaborações pedagógicas humanizadoras nas unidades escolares. Essa diretriz encaminha-nos a repensar os momentos de leitura e de contação de histórias com recursos que expressem a riqueza da literatura já impressa em livros, com suas tessituras, ilustrações e beleza.

Nessas 'Caixas' que contam tanto, há escolhas teórico-metodológicas direcionadas à inserção de crianças, e seus educadores, nas aventuras e fantasias, na melodia e na poesia, por meio de histórias "encantantes" e envolventes. Essa realização se dá a partir de expressões pedagógicas do trabalho desses educadores mediante a papietagem, o recorte, a colagem, a pintura, enfim, das artes em cores, palavras e formas.

Já as Oficinas de leitura - atividades especialmente realizadas nos municípios paulistas - dirigem-se ao letramento literário, diferente dos outros tipos de letramento, porque a literatura ocupa um lugar único em relação à linguagem, ou seja, cabe à literatura "tornar o mundo compreensível, transformando a sua materialidade em palavras de cores, odores, sabores e formas intensamente humanas" (COSSON, 2006b, p. 17).

É por entender essa singularidade que se define o letramento literário como "o processo de apropriação da literatura como construção literária de sentidos" (PAULINO; COSSON, 2009, p. 67). Por outro lado, não é apenas um saber que se adquire sobre a literatura ou os textos literários, mas sim uma experiência de dar sentido ao mundo por meio de palavras que falam de palavras, transcendendo os limites de tempo e espaço. Além disso, o letramento, feito com textos literários, proporciona um modo privilegiado de inserção no mundo da escrita, visto que conduz ao domínio da palavra a partir dela mesma. Por isso mesmo, o letramento literário precisa da escola para se concretizar, porque demanda um processo educativo específico que a mera prática espontânea de leitura de textos literários não consegue sozinha efetivar.

No Ler, contar e encantar crianças na Biblioteca Escolar, finalizada a contação de histórias, por exemplo, a proposta é o trabalho com as diferentes linguagens, já que podem ser tidas como atividades produtivas, cuja compreensão dos soviéticos (VIGOTSKY, 1995; MUKHINA, 1996) traduzem-nas como aquelas atividades que preveem o planejamento e a elaboração de um produto final, e que atuam de forma decisiva no desenvolvimento das crianças, preparando as bases para apropriações cada vez mais complexas. Ademais, trabalham com a ludicidade, criando espaço para a criança ocupar o seu lugar de sujeito capaz de elaborar seus próprios pensamentos por meio de uma síntese de todas as linguagens expressivas, comunicativas e cognitivas. Em nosso caso, novas relações articuladas à atividade da leitura literária, por meio da leitura e contação de histórias.

Com isso, justificamos também a defesa de uma abordagem multissimbólica nos trabalhos relacionados à Biblioteca Escolar. A partir das histórias lidas ou contadas, surgem relatos orais e escritos dos mediadores e das crianças; desenhos; dramatizações; modelagens, dobraduras e recortes; brincadeiras; construção de maquetes; 
pinturas. Os resultados dessas atividades podem ser apresentados na festa da biblioteca ou na festa da leitura ou ainda nos jornais, murais das turmas ou da escola; podem fazer parte de álbuns temáticos ou livros da vida; ainda podem ser endereçados, por meio da correspondência escolar, a crianças de outras cidades, estados ou países, criando novas interlocuções, inclusive de histórias da literatura e da cultura oral. ${ }^{4}$

Todas as atividades propostas buscam focar a textualização, que funciona, de modo geral, quando o escritor se põe a produzir um texto original. Ele começa com alguma(s) ideia(s) e usa o seu acervo de palavras, expressões idiomáticas, regras gramaticais, padrões retóricos e suas experiências passadas como leitor e escritor. $\mathrm{O}$ leitor e ouvinte (pensando no momento em que as crianças escutam, leem e objetivam sua compreensão por meio de diferentes linguagens) constituem-se em compartícipes de uma espécie de retextualização, na medida em que todo texto pode ser, a princípio, desdobrado em uma série de novos textos. De certo modo, todo texto é composto de vários textos, já que a sua interpretação varia de acordo com o leitor. Sabemos que a noção de que é possível criar efeitos semelhantes em leitores diferentes deve ser tratada com a maior cautela, pois é raro o caso em que dois leitores, mesmo de um poema, romance, de um livro de literatura infantil irão interpretá-lo da mesma maneira. Até o mesmo leitor interpretará um texto de modo diferente a cada vez que o ler, especialmente se a releitura acontece em intervalos distantes. Dessa forma, todas as atividades aqui assinaladas não são apenas um pretexto para trabalhar a ludicidade ou "preencher o tempo" sem articulação com o foco narrativo, mas precisam ser pensadas em articulação à compreensão textual.

Destarte, não podemos perder de vista que as histórias, os poemas, as cantigas devem ser lidos e contados pelo seu valor em si mesmos, porque tais textos podem, ainda, aguçar a escuta da criança. A criança, que é um dos maiores escutadores da realidade que a circunda, pode, por intermédio dessas atividades, escutar a vida nas suas formas, sons, cores; escutar os outros, adultos e pares. A criança é capaz de perceber que a escuta é um ato de comunicação que reserva maravilhas, alegrias, surpresas, entusiasmos, paixões e fantasias.

til:

Concordamos com Elias José, renomado autor-escritor da literatura infan-

Pais e professores, fiquem atentos se quiserem formar gerações de pessoas felizes e aptas a vencerem na vida. O livro infantil, que é oferecido para a criança ler, ou é lido para ela, caso não esteja alfabetizada ainda, é um brinquedo capaz de despertar o interesse pelas coisas sensíveis, criativas e inteligentes e belas. Através das histórias fictícias e da poesia, fazemos uma viagem de sonho e de puro encantamento. Aprendemos sem traumas, a lidar com problemas diários. Conhecemos melhor a realidade que nos cerca. Crianças e jovens que não tiveram o seu imaginário desenvolvido, aquecido pela leitura literária, pela dramatização, pelo poder de encantamento da música e das artes plásticas, serão pessimistas, endurecidos, incapazes de sorrir e de ser feliz (JOSÉ, 2007, p. 29).

A defesa do brincar e brincar com as histórias, personagens, formas e cores, além da realização de leituras carregadas de significado, atende às orientações extraídas dos escritos de Mukhina (1996). Essa autora, amparada na Teoria Histórico-Cul- 
tural, reafirma que a criança - nas experiências com as artes - estabelece comparações, elabora impressões, interpreta conflitos, considera diferentes hipóteses e desenvolve suas funções psicológicas superiores.

Sobre essa questão, Vigotsky (2007), em seus estudos sobre a imaginação e a criação na infância, inspira-nos a diferentes entendimentos. Um deles desafia-nos a repensar nossos planejamentos e intenções na educação das crianças. No interior das escolas, as práticas sociais com objetos culturais como os livros de literatura ou de poesias, as telas de pintura, as esculturas, por exemplo, podem constituir vivências e aprendizagens essenciais para que cada criança aprenda a compor e a criar (VIGOTSKI, 2007). Esse repertório de conhecimentos expressa-se em suas brincadeiras e outras diferentes formas de expressão infantis, tais como o desenho, a dança, a pintura, o recorte e a colagem, a dramatização, o faz-de-conta ou a brincadeira de papéis sociais.

A possibilidade de apropriar-se da cultura e de realizar "novas tarefas" e "novas atividades" (MUKHINA, 1996, p.284-285) se traduz como a necessidade da concentração para lembrar-se ou reproduzir algo ou mesmo proceder à elaboração de um desenho, ações que podem ser imediatamente associadas ao desenvolvimento da atenção, da memória e da imaginação, que ganham sentido com pintores e poetas. Sobre essa questão Mukhina (1996, p. 40) ensina que:

As crianças assimilam esse mundo, a cultura humana, assimilam pouco a pouco as experiências sociais que essa cultura contém, os conhecimentos, as aptidões e as qualidades psíquicas do homem. È essa a herança social. Sem dúvida, criança não pode se integrar a cultura humana de forma espontânea. Consegue-o com a ajuda contínua e a orientação do adulto - no processo de educação e de ensino.

Aqui, poderíamos destacar a apropriação da cultura e das realizações humanas que a criança pode fazer. Sobre essa ideia de apropriação das máximas elaborações humanas, nos é possibilitado pensar a partir dos escritos de Leontiev (1978). O que há de mais elaborado precisa ser apresentado às crianças, independentemente de sua idade e condição que ocupa nesta sociedade. Pensamos, aqui, em todo o rigor da escrita, toda a possibilidade de se conhecer a vida e se encantar com ela, os animais, os brinquedos, as aventuras, pela descrição encontrada em telas e textos. Salientamos que, para a Teoria Histórico-Cultural, figura como essencial a ação intencional do educador. Reportamo-nos ao bom ensino defendido por Vigotski, no conjunto de sua obra, ou do aprendizado e "ensino especial" ou "melhor ensino", tão pontuados na obra de Mukhina (1996, p. 50;236).

Nessa lógica, as escolas de Educação Infantil têm especial importância. Como a própria autora pontua, nesse período as atividades das crianças se tornam mais complexas, o que requer uma linguagem de melhor qualidade e reafirma a necessidade de não se utilizar qualquer livro, música ou poesia (MUKHINA, 1996). Cumpre observar o rigor na escrita, a qualidade do material e a definição dos contornos nos desenhos e letras, não encontrados nas folhas apagadas da fotocopiadora ou do mimeógrafo e em tantos outros materiais empobrecidos. Os autores soviéticos nos mostram, de modo contundente, que uma vida rica constitui um psiquismo rico de elaborações, portanto, uma educação enriquecida vai ao encontro desse postulado. 
Nesse contexto, é fundamental a atenção aos recursos, materiais e procedimentos. As escolhas, decisões e encaminhamentos dos coordenadores e educadores na rotina da instituição pode favorecer, ou não, a aprendizagem e o desenvolvimento das crianças. Então, não é antecipando-se práticas e conteúdos do Ensino Fundamental que se favorece, de forma sistematizada, a aproximação da criança com o conhecimento, as informações e as artes; ao contrário, é justamente respeitando o que é próprio da educação pré-escolar que o educador se instrumentaliza para seus procedimentos pedagógicos.

O enriquecimento do vocabulário e a primazia da linguagem favorecem a tentativa que a criança faz de compreender o significado das palavras, compará-las e associá-las. Segundo a autora, aprimorar a capacidade da criança para "construir frases de acordo com as regras gramaticais [...] contribuirá para o domínio da leitura e escrita" (MUKHINA, 1996, p. 234-235). Nesse sentido, acrescenta a autora, quando o ensino avança, abre-se caminho para o desenvolvimento psíquico com vista "à formação de determinadas qualidades psíquicas e à transformação de qualidades psíquicas adquiridas anteriormente" (MUKHINA, 1996, p.52).

Desse modo, o ensino, corretamente organizado, tem como objetivo mais do que a aquisição quantitativa de conhecimentos, pois centra-se no processo de desenvolvimento das funções psicológicas superiores, que se inicia na aquisição da linguagem oral espontânea e avança com a aquisição das demais formas de linguagem sistematizadas, como a escrita e a aritmética, entre outras. O objetivo central, por conseguinte, é a mudança qualitativa das funções que integram a consciência ou capacidade do indivíduo de controlar intencionalmente seu comportamento, as quais terão seu ápice de desenvolvimento nas formas mais elaboradas de pensamento, mediadas cultural e socialmente, promovidas no interior da instituição escolar (TULESKI, 2011).

O cerne do processo educativo está posto na produção de mudanças por meio de atividades pedagógicas cada vez mais enriquecidas que, mesmo reconhecendo as disposições naturais de cada criança, irão tê-las como base sob a qual se desenvolverão novas capacidades mediante a educação dirigida, a disciplina apropriada, a atividade criadora orientada para um fim e estimulada energicamente por incentivos sociais coletivos, tal como eram propostos os encaminhamentos educativos na sociedade de Vigotski, Luria e Leontiev (TULESKI, 2011).

\section{Algumas considerações}

Destacamos que experiências como essas de estudos e formação em serviço, que temos realizado, contribuem para, de um lado, aprimorar nossos projetos nas universidades e, de outro, mobilizar a constante avaliação das práticas pedagógicas executadas com as crianças. Outro elemento que julgamos essencial é a possibilidade de se motivar cursos e debates que reafirmem a possibilidade concreta de se implementarem ações pedagógicas amparadas pelos escritos da Teoria Histórico-Cultural; referencial teórico capaz de orientar propostas de atuação em uma perspectiva de humanização e emancipação.

As reflexões e proposições, expressas no presente estudo, apresentam-se enquanto possibilidades para realização de procedimentos e recursos didáticos ricos de significado, condição que, em nosso entendimento, deve figurar como essencial no 
processo de ensino, compreendendo que o bom ensino é aquele que possibilita o pleno desenvolvimento dos escolares, independente da faixa etária. Nesse sentido, os recursos didáticos mencionados, nessa reflexão, expressam os esforços das Equipes Pedagógicas e Secretarias municipais de Educação na tentativa - por vezes sem continuidade - de estruturar propostas de formação e intervenção pedagógica com vistas aos preceitos da Teoria Histórico-Cultural.

Seguindo esse referencial, temos claros três traços fundamentais da atividade consciente humana, de acordo com Luria (1991): o primeiro, que consiste no fato de o ser humano não estar obrigatoriamente ligado a motivos biológicos, sendo sua atividade regida por complexas necessidades, muitas delas superiores e intelectuais; o segundo, que seu comportamento não é completamente determinado por impressões evidentes recebidas do meio ou vestígios da experiência individual imediata, podendo abstrair, penetrar nas conexões e relações mais profundas das coisas, conhecer a dependência causal dos acontecimentos e interpretá-las; e o terceiro e último traço, que difere o ser humano do animal, afirmando que seu comportamento possui uma terceira fonte, a assimilação da experiência de toda a humanidade, acumulada no processo histórico-social e transmitida no processo de aprendizagem através do intercâmbio entre grupos e indivíduos mediados pela linguagem.

Do acima exposto, queremos reafirmar o dito desde o início, a relevância dos conhecimentos mais elaborados e da própria práxis educativa como imprescindíveis para o rompimento desse processo de naturalização das relações sociais de produção capitalistas. Além disso, ressaltamos que a perda do sentido e do significado, tanto dos conhecimentos que devem ser apropriados pelos alunos e transmitidos pelos professores, quanto das próprias atividades escolares, muitas vezes mecanizadas, fragmentadas e superficiais que alimentam e incrementam esse processo de alienação, apenas fazem com que as crianças e jovens não desenvolvam pelos trabalhos e atividades escolares motivos suficientes e tenham claras as finalidades do conhecimento científico e artístico para o seu desenvolvimento individual e da sociedade como um todo, mantendo-se na escola apenas por obrigação, motivados por notas, prêmios, classificações, títulos, status. "O estudante aprende assim a se desinteressar pelo conteúdo de seu trabalho, escolar primeiro e produtivo depois, e a se ajustar a um sistema extrínseco de recompensas" (ENGUITA, 1993, p.236). A unidade e inter-relação dos diversos campos de conhecimento se situam, muitas vezes, completamente alheias à experiência do aluno e do professor e "o ensino evolui no sentido de que cada um de nós saiba cada vez mais de cada vez menos" (ENGUITA, 1993, p.242).

Por fim, salientamos que as experiências pedagógicas destacadas, ao longo desse texto, procuram ir à contramão desse esfacelamento, contribuindo para que o professor possa reavaliar sua prática pedagógica com as crianças e consiga dar significado às suas ações nas escolas de Educação Infantil. Nessa perspectiva, personagens de telas, das canções, das poesias e histórias podem proporcionar uma aprendizagem que favoreça o trabalho pedagógico de dirigir a conduta da escola em favor da potencialidade humana. 
Marta Chaves - Silvana Calvo Tuleski Elieuza Aparecida de Lima

Cyntia Graziella G. Simões Girotto

\section{Referências}

BLAGONADEZHINA, L. V. Las emociones y los sentimientos. In: SMIRNOV, A. A.; LEONTIEV, A. N.; RUBINSHTEIN, S. L. e TIEPLOV, B. M. Psicologia. Trad. Florencio Villa Landa. 3. ed. México: Editorial Grijalbo, 1969, p.355-381.

BRASIL. Constituição da República Federativa do Brasil. 9. ed. São Paulo: RT, 2004.

. Lei n.9.394, de 20 de dezembro de 1996. Estabelece as diretrizes e bases da educação nacional. Diário Oficial, Brasília, DF, 23 de dezembro de 1996.

CHAVES, M. Intervenções pedagógicas e promoção da aprendizagem da criança: contribuições da Psicologia Histórico-Cultural. In: FAUSTINO, R. C.; CHAVES, M.; BARROCO, S. M. S. (Org.). Intervenções pedagógicas na educação escolar indígena: contribuições da Teoria Histórico-Cultural. Maringá: Eduem, 2008, p.75-89.

. Enlaces da Teoria Histórico-Cultural com a literatura infantil. In: CHAVES, M. (Org.). Práticas pedagógicas e literatura infantil. Maringá: Eduem, 2011a, p.97-106.

. A formação e a educação da criança pequena: os estudos de Vigotski sobre a arte e suas contribuições às práticas pedagógicas para as instituições de Educação Infantil. Araraquara, 2011b. Trabalho de Pós-Doutoramento junto à Faculdade de Ciências e Letras de Araraquara, Universidade Estadual Paulista "Júlio de Mesquita Filho"(Unesp), sob a supervisão do Prof. Dr. Newton Duarte.

COSSON, R. Letramento literário: teoria e prática. São Paulo: Contexto, 2006a.

COSSON, R. Letramento literário: educação para vida. Vida e Educação, Fortaleza - Ceará, v. 10, p.14-16, 2006 b.

ENGUITA, M. F. Trabalho, Escola e Ideologia: Marx e a crítica da educação. Porto Alegre: Artes Médicas, 1993.

FREINET, C. As técnicas Freinet da escola moderna. Lisboa: Estampa, 1975.

GIROTTO,C. G. .S.; SOUZA, R. J. de. A hora do conto na biblioteca Escolar: o diálogo entre leitura literária e outras linguagens. IN: SOUZA, R. J. Biblioteca Escolar e práticas educativas: o mediador em formação. Campinas: Mercado de Letras, 2009.

GIROTTO, C. G. G. S.; SOUZA, R. Estratégias de leitura: para ensinar alunos a compreenderem o que lêem. In: SOUZA, R. (Org.) Ler e compreender: estratégias de leitura. Campinas, Mercado de Letras, 2010.

JOSÉ, E. Literatura Infantil. Porto Alegre: Mediação, 2007.

LEONTIEV, A. N. O desenvolvimento do psiquismo. Lisboa: Livros Horizonte, 1978.

. Uma contribuição à teoria do desenvolvimento da psique infantil. In: VIGOTSKII, L.S.; LURIA, A.R.; LEONTIEV, A. N. Linguagem, desenvolvimento e aprendizagem. São Paulo: Ícone, 1988, p.59-83.

LIMA, E. A.; VALIENGO, A. Literatura infantil e caixas que contam histórias: encantamentos e envolvimentos. In: CHAVES, M. (Org.). Práticas pedagógicas e literatura infantil. Maringá: Eduem, 2011, p.55-68.

LURIA, A. R. The problem of the cultural behavior of the child. In: __. The Vygotsky reader. Editado por René van der Veer and Jaan Valsiner, Cambridge, USA: Blackwell Publishers, 1994b.

MELLO, S. A.; FARIA, A. L. G. (Orgs.) . Linguagens Infantis: outras formas de leitura. 1.ed. Campinas: Autores Associados, 2005. 
MUKHINA, V. Psicologia da Idade Pré-escolar. Trad. Claudia Berliner. São Paulo: Martins Fontes, 1996.

PAULINO, G.; COSSON, R.. Letramento literário: para viver a literatura dentro e fora da escola. In: ZILBERMAN, R.; RÖSING, T. (Orgs.). Escola e leitura: velha crise; novas alternativas. São Paulo: Global, 2009.

SMIRNOV, A. A.; LEONTIEV, A. N.; RUBINSHTEIN, S. L.; TIEPLOV, B. M. Psicologia Trad. Florencio Villa Landa. 3. ed. México: Editorial Grijalbo, 1969.

TULESKI, S. C. A relação entre texto e contexto na obra de Luria: apontamentos para uma leitura marxista. Maringá: EDUEM, 2011.

VIGOTSKII, L. S. Aprendizagem e desenvolvimento na idade escolar. In: VIGOTSKII, L. S.; LURIA, A. R.; LEONTIEV, A. N. Linguagem, Desenvolvimento e Aprendizagem. São Paulo, Ícone: Edusp, 1988, p. 103-117.

VYGOTSKI, L. S. Problemas del desarrollo de la psique. Obras Escogidas. Madrid: Visor, v. 3, 1995.

VIGOTSKY, L. S. La imaginación y el arte en la infancia: ensayo psicológico. 8. ed. Madrid: Akal, 2007 (Akal básica de bolsillo, 87).

VYGOTSKY, L. S.; LURIA, A. R.. Tool and symbol in child development. In: The Vygotsky reader. Editado por René van der Veer and Jaan Valsiner, Cambridge, USA: Blackwell Publishers, 1994.

\section{Notas}

${ }^{1}$ Indianópolis, Região Noroeste, formação realizada em 2002 intitulada "Desafios da Prática Educativa: diálogos e conquistas de professores e crianças”; Presidente Castelo Branco, Região Noroeste, formação realizada em 2005 e 2006 denominada "Professores Repensando a Prática: propostas, objetivos e conquistas coletivas”; Alto Paraná, Região Noroeste, formação realizada em 2006 denominada “Teoria Histórico-Cultural e Práticas Educativas: conquistas de professores e crianças da Educação Infantil”; Telêmaco Borba, Região Sul, formação realizada em 2006 denominada "Práticas Pedagógicas e Literatura Infantil: conquistas de professores e crianças"; Lobato, Região Noroeste, formação realizada em 2009 denominada "Letras, números, pincel e tinta: sempre é hora de brincar e aprender”; Planaltina do Paraná, Região Noroeste, formação realizada em 2009 denominada "Estudos e Práticas Educativas: desafios e conquistas de Educadores e Crianças”; Terra Rica, Região Noroeste, formação realizada em 2010 e 2011 denominada "Teoria Histórico-Cultural e Práticas Educativas Humanizadoras: o desafio da formação continuada" no ano de 2010 e Santa Inês, Região Norte Central, com a formação denominada: "Teoria Histórico-Cultural e Intervenções Pedagógicas Humanizadoras: realizações e vivências possíveis com educadores e crianças”, iniciada em 2011 com previsão de continuidade em 2012.

2 Trabalhos de Extensão Universitária: no Distrito de Padre Nóbrega, Marília (SP), Região Oeste Paulista, "Pedagogia de Projetos: (re)significação do processo ensino-aprendizagem"(2001 a 2003); Distrito de Santa Therezinha em Lupércio (SP), "Os projetos de leitura e escrita nas séries iniciais do ensino fundamental"; municípios de Marília, Oscar Bressane e Quintana (SP) "Projetos Didáticos com a língua materna: uma alternativa de trabalho para a formação de leitores e produtores de textos” (2003 a 2005); município de Marília (SP), "Ler e escrever em contextos significativos: contribuições da Metodologia de projetos e da Teoria Histórico-Cultural.”(2006 e 2007); “Atividades de leitura literária: mediações para o aprendizado da leitura e da escrita" (2008 e 2009); "Leitura e contação de histórias: janelas ao sonho e à reflexão" (20062010); "Ensino das estratégias de leitura e literatura infantil na escola: processos de partilha e iniciativa à atividade infantil na formação da criança leitora" (2011); "Articulações necessárias entre a educação infantil e o primeiro ano do ensino fundamental: Brincadeiras, brinquedos e brinquedotecas" (2010- 2011) e "Brinquedotecas: Espaços de Formação Cultural de Professores e Crianças” (2011). 
Marta Chaves - Silvana Calvo Tuleski Elieuza Aparecida de Lima

Cyntia Graziella G. Simões Girotto

${ }^{3} \mathrm{O}$ recurso didático denominado Caixas de Encantos e Vida é elaborado coletivamente, o grupo realiza a escolha de um expoente da literatura, da poesia, da música ou das artes plásticas a ser estudado. A Caixa contempla os "encantos" que, em geral, é representado por cinco temáticas, quais sejam: infância, amigos, obra, viagens e realizações que dizem respeito ao reconhecimento ou premiações que tenha obtido ao longo de sua trajetória profissional. O objetivo é representar a "vida" de um determinado expoente a partir de material escrito, fotos e objetos que caracterizem os diferentes momentos de sua história. Este recurso didático possibilita o desenvolvimento de atividades com a participação direta e indireta das crianças, fazendo com que participem ativamente no processo de tomada das decisões e elaboração dos conteúdos a serem desenvolvidos, permitindo com isso uma aprendizagem significativa (CHAVES, 2011b). As Caixas de Encantos e Vida foram especialmente desenvolvidas junto ao Município de Terra Rica-PR, no ano de 2011.

${ }^{4}$ Essas últimas propostas advêm do estudo das técnicas Freinet (1975).

* Professora Doutora da Universidade Estadual de Maringá, Maringá, Paraná, Braisil.

** Professora Doutora da Universidade Estadual de Maringá, Maringá, Paraná, Braisil.

*** Professora Doutora da Faculdade de Filosofia e Ciências da Universidade Estadual Paulista - Campus de Marília, Marília, São Paulo.

**** Professora Doutora da Faculdade de Filosofia e Ciências da Universidade Estadual Paulista - Campus de Marília, Marília, São Paulo.

\section{Correspondência}

Marta Chaves - Universidade Estadual de Maringá, Centro de Ciências Humanas Letras e Artes, Departamento de Teoria e Prática da Educação. Av. Colombo, 5790 Zona 07, CEP: 87020-900 - Maringa, Paraná - Brasil.

E-mail: mchaves@wnet.com.br - silvanatuleski@gmail.com - aelislima@ig.com.br - cyntia@marilia. unesp.br

Recebido em 14 de novembro de 2012

Aprovado em setembro de 2013 